\title{
Studying incremental institutional change: A systematic and critical meta-analysis of the literature from 2005 to 2015
}

\section{Jeroen van der Heijden and Johanna Kuhlmann}

\section{Accepted for publication in PSJ}

\begin{abstract}
Since the early 2000s, theorising on incremental institutional change has made inroads in comparative historical analysis. In particular, the ideas, concepts, and theory introduced by Kathleen Thelen and her collaborators have been widely adopted by scholars. These scholars are not, however, univocally positive about the theory. Three main critiques have been plaguing the theory since its early days: the concepts it builds on lack clarity; the model of agency it uses is too static; and the theory lacks analytical power overall. Following the PRISMA method, this article presents a meta-analysis of the peer-reviewed empirical literature from 2005 to 2015 that applies this theory. It seeks to better understand the reach of the critiques expressed, as this may provide a starting point for improvement. It finds considerable quantitative support for the critiques, and uncovers an additional problematic issue: the tendency for concept stretching and concept proliferation by scholars seeking to overcome the shortcomings of the theory. Paradoxically, concept stretching and proliferation only further reduce the analytical power of the theory. The article concludes with suggestions for improvement of the development and application of the theory.
\end{abstract}




\section{Keywords}

Comparative historical analysis, incremental institutional change, layering, conversion, drift, displacement, exhaustion, gradual institutional change, historical institutionalism, PRISMA meta-analysis.

\section{Introduction}

In studying political processes, scholars can turn to a variety of theories on institutional change (for reviews, see Capano \& Howlett, 2009; Rhodes et al., 2006; van der Heijden, 2013; Koning, 2016). When reviewing these theories, a broad distinction can be made between those that are studying major changes that were implemented at critical junctures in time or as a result of exogenous shocks (e.g. Baumgartner \& Jones, 1993; 2009), and those that are studying incremental change (Pierson, 2004; Hall, 2015; Mahoney \& Thelen, 2015).

A focus on incremental change is relevant. It may help us to better understand why and how, without responses to major exogenous 'shocks', policies over time nevertheless show major change (Thelen, 1999). It may also help us to better understand how relatively small policy changes may over time have accumulative effects on society. These can be negative, as in the example of how ongoing minor changes to the Federal Aid Highway Act have arguably resulted in deterioration of the United States' infrastructure (Mettler, 2016), or positive, as in the example of how the Netherlands' national government has been chipping away municipal authority in the regulation of buildings since 1901 to achieve a high and consistent level of building safety throughout the country (van der Heijden, 2016).

In studying incremental institutional change, specifically the work of Kathleen Thelen has become dominant (Campbell, 2010; Hall, 2015). She and her collaborators-including Jacob 
Hacker, James Mahoney, Paul Pierson, and Wolfgang Streeck—have introduced an innovative theory that identifies and conceptualizes different modes of incremental change in ways that allow for nuanced descriptions and analyses of incremental change at various institutional levels (including policy and regulatory regimes), in a wide variety of contexts, involving a range of different actors and actor constellations (Streeck \& Thelen, 2005; Mahoney \& Thelen, 2010; Hacker, Pierson, \& Thelen, 2015).

Consequently, their theory has enjoyed a broad reception. Scholars applying it are, however, not univocally positive about it. Whilst some laud it for having provided helpful language and heuristics to explain gradual institutional change, others critique it for lacking analytical rigour and being too descriptive. Three main points of critique stand out (Hall, 2015; van der Heijden, 2013). First, the modes of change introduced, their definitions, and boundaries lack clarity. Second, the theory builds on a static model of agency in understanding incremental change. Third, and related to these two points, the theory lacks analytical and explanatory power. Whilst such critiques have been expressed by various scholars (further highlighted in what follows), they often build on small-N empirical studies or non-systematic reviews of the literature. In other words, the critiques are mainly qualitative and we lack insight into their accuracy and reach. As such, the critiques are not helpful as a starting point for improving the theory, its application, or both.

In this article, we take these recurring critiques as a starting point in assessing Thelen and her collaborators' theory on incremental policy change. Applying PRISMA methodology (explained in what follows), we present a systematic meta-analysis of the peer-reviewed literature that builds on this theory (or claims to do so) from the period 2005-2015. In doing so, we contrast critiques with empirical findings, and we synthesize insights from the works that have applied the theory. Two key findings stand out. First, our meta-analysis supports all three points of critique, raising further questions about the analytical power of the theory. 
Second, to overcome experienced shortcomings of the theory, scholars tend to stretch existing concepts and introduce new ones (concept proliferation). This has, however, the undesired side effect that the analytical power of the theory is only further reduced. We conclude the article with suggestions for future development and application of the theory.

\section{Theorising on gradual institutional change: Modes of change, change agents and assumed causality}

Before we move to our review of the literature, it is useful to introduce the theory developed by Thelen and her collaborators-readers who are very familiar with this theory might wish to move straight to the meta-analysis presented in the sections that follow.

Analysing the literature on institutional change, Thelen finds that 'it is not so useful to draw a sharp line of institutional stability versus change' (Thelen, 2000, p. 106; emphasis in the original). Historical institutionalism has provided her with the tools to keep that line somewhat flexible. For Thelen, the tool to analyse incremental institutional change is path dependency, 'which involves elements of continuity and (structured) change' (Thelen, 1999, p. 384). This insight might be considered to be a deviation from a long-standing tradition in studying institutional change (Hall, 2015; Weishaupt et al., 2013). Drawing on this, Thelen has worked for a long time on alternative ways of theorising institutional change, and particularly incremental but substantial change. In doing so, she has collaborated with a large number of scholars who should be credited just as much for developing and strengthening this theory.

Over time, these scholars have distinguished five modes of incremental change: layering, conversion, drift, displacement, and exhaustion. It is in the introduction and conceptualizing of these modes that their work has been particularly innovative and widely followed 
(Campbell, 2010; Béland, 2010). They were first pooled in Streeck and Thelen's Beyond Continuity (2005) and further developed in Mahoney and Thelen's Explaining Institutional Change (2010).

There are, however, some notable differences between these seminal books. First, the modes of change are introduced using (slightly) differing terminology — and in other works by Thelen and her collaborators again (slightly) different terminology is used (van der Heijden, 2010). There does not seem to be a 'correct' or confined definition for any of the modes of incremental change. The following brief discussions of each mode should be considered in that light.

- Layering refers to a situation of gradual institutional change through a process in which new elements are added to existing institutions. What is essential about layering is that the new elements do not replace existing ones, but are added to these and so gradually change their status and structure. In using the term, Thelen was inspired by the work of Eric Schickler (2001).

- Conversion refers to a situation of redeployment or reinterpretation of existing elements of an institution for new purposes. It holds that institutions themselves do not change but are harnessed to serve new ends by actors that are in, or are affected by, an institutional setting. In using this term, Thelen was inspired by the work of Wolfgang Streeck (1997). ${ }^{1}$

- Drift refers to a situation where there is a changed impact of existing institutions or elements in it due to shifts in the institution's environment and a lack of adjusting the institutions to these. The conceptualisation of this mode strongly leans on the work of

\footnotetext{
${ }^{1}$ Notably, Edward A. Koning (2016,Footnote 8) argues that this process was earlier referred to as 'institutional transposition’ by Philipp Genschel (1997).
} 
Jacob Hacker (2004). Hacker considers drift an unintended consequence of not updating existing institutions, but argues it might as well be an intended strategy for some actors: 'it may be the result of active attempts to block adaptation of institutions to changing circumstances' (Hacker 2004, p. 248). Drift is closely related to conversion, but differs from it, as under conversion the implementation and use of institutions change, whilst with drift changing circumstances alter the effects of institutions and policies (Hacker, 2004; Hacker, Pierson, \& Thelen, 2015).

- Displacement refers to a situation in which 'new models emerge and diffuse which call into question existing, previously taken-for-granted organizational forms and practices' (Streeck \& Thelen, 2005, p. 19). Whilst closely related to layering, it differs from it because with displacement the new eventually replaces the old, whilst with layering the old remains in place. Displacement relates to ideas on mimicry and institutional isomorphism (DiMaggio \& Powell, 1991), and Thelen refers to these as her sources of inspiration. She considers displacement to be 'rare in the politics of reform in contemporary advanced capitalist economies' (Thelen, 2009, p. 488). To her, displacement is a consequence of another mode of incremental change rather than a stand-alone mode in itself (Streeck \& Thelen 2005).

- Exhaustion refers to a "process in which behaviors invoked or allowed under existing rules operate to undermine these ... [leading to] institutional breakdown rather than change' (Streeck \& Thelen, 2005, p. 29). In Explaining Institutional Change, Mahoney and Thelen are hesitant to include this form of incremental change within the group discussed earlier, precisely because it does not so much address institutional change as institutional breakdown.

In Explaining Institutional Change exhaustion is no longer included, which can be regarded as a second main difference between the two books. A third notable difference is that in 
Explaining Institutional Change Mahoney and Thelen seek to go beyond the pure classification of the modes, and hypothesize causal links to explain incremental change through them. In doing so, the book moves from rather loose theorising on incremental change (which is an often expressed critique of Beyond Continuity, extensively discussed in what follows) to presenting a more formal theory by bringing various expectations together in a heuristic framework-illustrated in Figure 1.

\section{FIGURE 1 ABOUT HERE}

In Explaining Institutional Change, Mahoney and Thelen systematically link the opportunities of actors within a political context for pursuing or preventing changes to a targeted institution to the modes of change. They consider two characteristics as explanatory: First, the context might afford defenders of the status quo strong or weak veto possibilities (i.e., to what extent can they block change?). Second, the targeted institution might afford political actors considerable or little opportunities for exercising discretion in interpreting or enforcing it (i.e., to what extent can they find an opportunity for change?). The explanatory characteristics as well as the heuristic framework introduced by Mahoney and Thelen strongly build on the work of Jacob Hacker (2004), who presents a 2x2 diagram as well.

Whilst the causal relationship between the characteristics and modes of change is presented clearly in their heuristic (Figure 1), Mahoney and Thelen go through a complex discourse and thought process to support the allocation of the combination of high or low veto possibilities and high or low discretion to each of the four modes of change. Rather than explaining how a mode of incremental change relates to a specific combination of characteristics (a context), they discuss how the mode is most likely not associated with the three other contexts. They 
then assume that 'likely not associated' is the opposite of 'likely associated' and assign the mode to the remaining context (van der Heijden, 2010). This assumption is risky, however, for two reasons. First, it assumes that the modes of change are mutually exclusive and that the set of modes covers all possible forms of change. This is not the case, as earlier Thelen and her collaborators identified at least five modes, and the broader literature has long been critical about the modes not being mutually exclusive (see our earlier discussion, more extensively discussed in what follows). Second, it assumes multilateral causality in how the combined characteristics relate to the modes of change (the problem of assumed symmetry; see further Popper, 2002 [1935]). When Mahoney and Thelen wrote their book there was no (empirical) support for this assumed symmetry (and there still isn't). The then available evidence base would only have allowed for a unilateral causal discourse - how things are related, or how they are not related - and not for deducing what is 'likely' from what is 'likely not'.

Their complex discourse results in an allocation of modes of change and characteristics that show considerable differences with how Hacker (2004) allocates them - this while all authors use highly comparable characteristics and modes of change. ${ }^{2}$ Mahoney and Thelen do not explain why exactly they allocate the modes of change differently from Hacker's model.

A fourth and final notable difference between the two books is the introduction of change agents in Explaining Institutional Change. Change agents are conceptualised as those actors

\footnotetext{
${ }^{2}$ Strikingly, whereas drift and conversion were both linked to situations of a high level of ambiguity of rule interpretation in Explaining Institutional Change (see Figure 1), in a later contribution to the literature, Thelen and her collaborators drift is linked to a low level of ambiguity and conversion to a high level of ambiguity (Hacker, Pierson, \& Thelen 2015). Another striking difference is that in this later contribution, Thelen and her collaborators link drift and conversion to a strong status quo bias, while in Explaining Institutional Change, drift is linked to strong veto possibilities and conversion is linked to weak veto possibilities.
} 
in an institutional setting that seek change or seek to prevent change. Again, two characteristics are introduced as explanatory: An actor may seek to preserve the existing institution (or not), and an actor may follow the rules of it (or not). By crossing these two characteristics, Mahoney and Thelen come to a typology of four types of change agents (ibid. 22-27). Each change agent is uniquely linked to one mode of change:

- Insurrectionaries, change agents that seek to eliminate existing institutions by actively mobilizing against these. Mahoney and Thelen expect them to be most successful in a situation of low veto powers and low discretion-i.e., when an institution cannot easily deal with change, and when proposals for change cannot be stopped easily. They are linked to displacement accordingly.

- Parasitic symbionts, change agents that exploit an institution for private gain and in doing so undermine the institution over time; they, however, seek to maintain the institution. ${ }^{3}$ They are expected to be most successful in a situation of high veto power and high discretion - i.e., over time these change agents have learnt how to exploit an institution and know how to get away with it. They are linked to drift accordingly.

- Subversives, change agents that seek to displace an institution, but instead of actively mobilizing against it, they try to destroy the institution by working within it. They are expected to be most successful in a situation of high veto powers and low discretion and are linked to layering.

- Opportunists, these are the most complex change agents in the book: Mahoney and Thelen suggest that they can either seek to preserve an institution or not, and can either follow its rules or not. Still, they are uniquely linked to conversion. Their logic

\footnotetext{
${ }^{3}$ Mahoney and Thelen also introduce the variety of mutualistic symbionts, but do not link these to a specific mode of change.
} 
for this link is that through the conversion of an institution they may redirect it in such ways that it still serves their own ends.

After having presented the main concepts of the theory on gradual institutional change developed by Thelen and her collaborators, the next section discusses the methodology we have followed to assess how these concepts have been applied in the empirical literature since 2005.

\section{Methodology}

The theory has been enjoying a broad reception. Sourcing a number of online databases (Google Scholar, World Cat, JSTOR, Web of Science), we found that by 2015, Beyond Continuity was cited in some 1,350 works; ${ }^{4}$ and Explaining Institutional Change in a little over 700. Excluding overlaps in citations (close to 250 cite both books), we can conclude that over 1,800 works individually cite these books.

Considering the core research area of these books - incremental and gradual institutional and policy change — we have found a little over 450 works in the same period (2005-2015) that refer to 'gradual institutional change' or 'incremental institutional change' without citing these two books or other work by Thelen and her collaborators. We further found a little under 750 works that refer to 'gradual policy change' or 'incremental policy change' without

\footnotetext{
${ }^{4}$ The numbers presented should be understood as giving an indication of quantitative differences in the use of the theorizing introduced by Thelen and her collaborators. Particularly for numbers exceeding 250 we do not claim they are exactly accurate. This is a direct result of the databases we have sourced. None of the databases guarantees that it can access all the works available around the globe. Google Scholar is, for example, very honest about this issue and mentions that the sources it finds are 'about' so and so many, and not absolute numbers. We therefore refrain from giving exact numbers that are larger than 250 .
} 
acknowledging the work of Thelen and her collaborators. Excluding overlap, we can conclude that between 2005 and 2015 around 1,000 works in the area of incremental and gradual institutional and policy change were published that do not refer to the work of Thelen and her collaborators - considerably less than the over 1,800 works in this area that do acknowledge their work. But what can be concluded from the existing body of work that builds on this theory?

At present, there is no agreed upon method of qualitative research synthesis, and often metareviews of the policy literature lack any method or explanation thereof (Carey \& Crammond, 2015). In this article, we follow the PRISMA method (the Preferred Reporting Items for Systematic Reviews and Meta-Analysis). ${ }^{5}$ PRISMA is an evidence-based minimum set of items for reporting in systematic reviews. Central to PRISMA is making transparent the motivations for including and excluding works in the meta-review. A flow diagram (Figure 2) visualizes the transition from identified works to works included in the present literature review.

FIGURE 2 ABOUT HERE

Here, we are particularly interested in how scholars have applied Thelen and her collaborators' theory in empirical studies. To come to a workable database of records that are likely empirical, we have carried out automated full-text searches of the 1,800+ records for phrases that point to original empirical work. We have casted a broad net to identify potentially empirical records by screening the $1,800+$ for the following phrases: 'this

\footnotetext{
${ }^{5}$ www.prisma-statement.org (6 July 2016).
} 
empirical', 'our empirical', 'my empirical', 'new finding', 'novel finding', 'new data', 'novel data', 'new insight', and 'novel insight'. Of the full set, a little over 1,600 records did not contain any of these phrases and were removed from the analysis. This resulted in a set of 216 records that cite one or both key works and are likely empirical. We acknowledge that the set of search phrases may have excluded existing empirical works from our meta-analysis. The full body of empirical work is, therefore, likely larger. ${ }^{6}$

This set of 216 records was then studied for quality. We identified 107 articles published in peer-reviewed journals, 25 books or book chapters, and a set of 84 records including conference submissions, working papers, $\mathrm{PhD}$ theses, and unpublished manuscripts. We realised that many books and chapters had appeared as peer reviewed articles as well. These were considered as duplicates in the set of records and removed from the systematic analysis (but not from the broader discussion in this review article). We also excluded the set of 84 other records, as the vast majority had not gone through rigorous peer review. The remaining set of 107 records (all peer-reviewed journal articles) was then screened for authorship. We have excluded 5 articles written by the core group of Thelen and her collaborators, and those by the authors of this article.

The remaining set of 102 articles was then fully read, and systematically screened for two issues: First, whether they apply Thelen and her collaborators' work or merely reference it. Of the 102 articles, 54 apply their work, while the remaining 48 merely reference it - for example, the work of Thelen and her collaborators is often 'obligatory' cited as an example of 'another' school of institutionalism (e.g., Beramendi \& Rueda, 2014). Second, whether they

\footnotetext{
${ }^{6}$ An alternative way to come to a workable set of records could have been a fully random selection. That ran the risk, however, that even more empirical records would have been omitted from our analysis. The full overview of the results of the PRISMA analysis of these 216 articles is available from the authors upon request.
} 
indeed build on empirical data or slipped through the broad net of identifiers cast. We identified 81 articles that build on novel empirical data. The other 21 articles are either fully theoretical or refer to secondary data (empirical research by others) as illustrations for theoretical claims - indicating that the net we cast was reasonably successful at identifying empirical records. Combined, this step resulted in a pool of 45 articles that apply the theory and are empirical. This set of 45 articles is at the base of the meta-analysis that follows.

\section{Findings: Three main existing critiques and a novel one}

In what follows we structure our meta-analysis around three major critiques that have over time been expressed about the theory: First, that the modes of change introduced, their definitions, and boundaries lack clarity; second, that the theory builds on a static model of agency in understanding incremental change; and third and related, that the theory lacks analytical and explanatory power. We conclude this section by introducing an additional critique that resulted from the meta-analysis. In seeking to overcome the limitations of the theory, scholars often stretch existing concepts or introduce new ones (concept proliferation). This has, however, the undesired side effect that the analytical power of the theory is only further reduced.

\section{Critique to the modes of change}

The modes of change have been mostly critiqued for lacking conceptual clarity (e.g., Barnes, 2008; Béland, 2007; Hudson et al., 2008; Immergut \& Anderson, 2008; Seeleib-Kaiser \& Fleckenstein, 2007; Gozman \& Currie, 2014). Over the years, scholars have pointed out, furthermore, that the boundaries of the modes overlap, which makes it difficult to clearly 
distinguish one mode from another (e.g. Steinlin \& Trampusch, 2012;). For example, sometimes layering can also be understood as drift or conversion. In such situations, it is then up to the researcher to make the call concerning what is actually observed (Ackrill \& Kay, 2006; Duit, 2007; Thatcher \& Coen, 2008).

Despite these recurring critiques, our PRISMA analysis indicated that the modes of change are particularly popular when studying gradual change: 40 articles of the 45 articles included in the meta-analysis focus on any of the modes (89\%), 23 focus on more than one mode (51\%), and only 5 do not specifically focus on any mode at all (11\%). Of the modes introduced, layering has received the most attention. It was mentioned in 31 of the articles included in the meta-analysis $(69 \%)$. With the exception of exhaustion, all the other modes were mentioned frequently also. Conversion was empirically observed in 17 articles (38\%), displacement in $16(33 \%)$, drift in $12(27 \%)$, and exhaustion in a mere $2(4 \%)$.

What is striking from this part of the meta-analysis is, especially, the scarcity of exhaustion as well as the frequency of layering in empirical analyses of gradual institutional change. The relative neglect of exhaustion is remarkable, because when considering the broader institutional and policy change literature, we would not expect institutional breakdown to occur so rarely. However, it might be possible that scholars analysing institutional breakdown rely on other theoretical literature than that introduced by Thelen and her collaborators. With regard to layering, it needs to be stated that it remains an open question whether layering is most frequently observed in empirical studies because it actually occurs more often than the other modes, or because it is easier to observe than the other modes (cf., Valman, 2013; Hacker, Pierson, \& Thelen, 2015).

Our meta-analysis supports critique to overlapping boundaries. Scholars repeatedly point to sequences of modes of change, rather than clearly defined and bounded modes of change. For example, 'layering is the means by which conversion ultimately occurs; the two processes are 
intimately interconnected' states Boas (2007, p. 50). Such sequencing is repeatedly referred to in the literature - and in 13 articles it was empirically observed (29\%). Some scholars go even further and argue that a mode can best be understood as 'a transitional stage of institutional development, not a final result' (Barnes, 2008, p. 637). Examples of modes going through such transitional stages abound. To name a few: From layering to conversion (Boas, 2007, Shpaizman, 2014), conversion to layering (Sheingate, 2010), layering to displacement (Ellingsæter, 2014), and drift to layering (Emmenegger, 2015). Barnes identifies a more complex sequence from drift to conversion to layering (Barnes, 2008), and Lambert one that moves from layering to conversion to displacement (Lambert 2016). The empirical reality of such transitioning or sequencing of modes makes it difficult for scholars to capture a concrete case of incremental change in the confined modes provided by Thelen and her collaborators.

Our meta-analysis further supports critique that the modes of change lack conceptual clarity. Are they strategies used intentionally by change agents? Are they processes that, intentionally or not, unfold over time? Or are they simply the outcomes of processes of institutional change? Scholars have empirically observed all possibilities (and sometimes also more than one possibility at a time). In our meta-analysis, we traced 9 examples of the modes of change as a strategy (20\%), 26 as a process (58\%), and 20 as an outcome (44\%). Without being clear about what a mode of change exactly is, it is difficult to compare cases that identify similar modes of gradual institutional change - a point we will return to later.

\section{Critique to a static model of agency}

One of the main innovations of Explaining Institutional Change is the introduction of the four change agents, and the links between these actors and the four modes of change (see Figure 1). Yet, scholars have been particularly critical to this model of agency as being too static for 
studying observed instances of incremental change and actors involved (Lomazoff, 2012; ; van der Heijden, 2010). They further have pointed out that the set of explanatory variables is too narrow to study real world examples of institutional change involving these change agents, and that even more than the modes of change the change agents lack conceptual clarity (Rocco \& Thurston, 2014).

Our meta-analysis points out that while the modes of change are the central focus in the empirical studies (namely in $89 \%$ of the articles included in the meta-analysis; see above), the change agents prove to have been less of a central focus in the empirical literature. Of the 45 articles included in the meta-analysis, 32 were published after 2010-i.e. after Explaining Institutional Change appeared. Of these 32 articles, 13 mention change agents as conceptualised by Thelen and her collaborators (40\%), but only 6 apply change agents in their empirical work (19\%; see Angelin et al., 2014 for an outstanding examples). Those applying change agents often argue that there is a gap between theoretical expectations and empirical findings, which in part is a result of the narrow set of explanatory characteristics introduced by Thelen and her collaborators). Consequently, scholars have sought to expand the set of explanatory variables introduced in order to better understand concrete cases of change were change agents are involved (e.g., Rocco \& Thurston, 2014)—a point we will return to later. A specific insight that stands out from our meta-analysis is that the static model of agency is undermined by empirical observations of sequencing. The mere observation of sequencing indicates that in explaining incremental institutional change more is at stake than the two characteristics and four types of agents introduced in Explaining Institutional Change (see Figure 1). At the very least, the possibility of sequencing indicates that similar agents might seek change through different modes, possibly within similar contexts. This, however, contradicts the causal relationships expressed by Mahoney and Thelen (2010), who uniquely assign contexts and agents to an individual mode of change (see related discussions in 
Maggetti, 2014; Rocco \& Thurston, 2014). Of course, real-world change agents might switch their roles or strategies to achieve their goals (say, from opportunist to subversive — seeking conversion through layering). As with the modes of change, there might be a sequencing of change agents in concrete cases of gradual change (see also Nichols, 2015).

Critique regarding the analytical and explanatory power of the theory

A third recurring point of critique follows from the former two-scholars are critical to the analytical and explanatory power of the theory (e.g., Ackrill \& Kay, 2006; Béland, 2007; Shpaizman 2014). With so much ambiguity in key concepts (modes, change agents, context characteristics), overlapping boundaries of the modes of change, and the static causal model of change agents it is unlikely that the theory is capable to fully explain observed instances of gradual change.

Indeed, our meta-analysis points out that of the 45 articles, 19 articles make detailed recommendations to change the theory and heuristics because of the limited explanatory reach of the theory (42\%). These range from adding modes of change (we will discuss this aspect below) and change agents (Funk \& Hirschman 2014) to expanding the set of explanatory variables (Barnes, 2008, Fenger et al. 2014). For example, adding the notion of 'ideas' as an explanatory variable (e.g., Béland, 2007; Parker \& Parenta 2008; Shpaizman, 2014), or adding the notion of 'spatial' change to the notion of temporal change (Ackrill \& Kay, 2006). At the same time, however, 17 articles explicitly stated that the theory had been helpful for the studies they presented (38\%). Yet, most of these used the modes of change, change agents, and other concepts loosely as an 'accepted' language to describe empirical observations rather than to evaluate them. 
Here, another noteworthy insight stands out from our meta-analysis also. When considering the various theoretical expectations expressed in Explaining Institutional Change, we found very limited empirical testing of these. Of the set of 31 articles included in the meta-analysis that has appeared since the publication of this book, only 12 directly assess the expectations introduced, i.e. the characteristics of the institutional context and the characteristics of the targeted institution (39\%). What is more, these articles often focus on one or two modes of change, and not all four (or five, if exhaustion is taken into consideration as well), and generally do not assess expectations about the change agents (see also above). Most interesting is that, of these 12 articles, we identified only one article that explicitly confirms the theoretical expectations (Lambert, 2016); the other 11 articles either fully or partly disconfirm them or need to introduce more theories in order to be able to work with the modes of institutional change and explain causal relationships.

In this regard, a final issue that struck us in carrying out the meta-analysis is that from the 45 articles, only Todd's analysis seeks to better understand what may be considered a failed attempt of gradual institutional change (Todd, 2011). The other articles included in the PRISMA analysis look, in one way or another, at successful gradual change. This is striking because Thelen and her collaborators repeatedly mention how change agents can use the modes of change strategically to seek or hamper institutional change. It could be, of course, that it is more complicated to identify or study cases of failed change than cases of successful change.

\section{A novel critique: the risks of concept stretching and concept proliferation}

Having assessed the three main forms of critique of the theory, and having found considerable quantitative support for them, we realised that our meta-analysis pointed to an issue that has 
not had much attention in the literature yet (but see Rixen \& Viola, 2015). Scholars applying the theory often seek to overcome its limited explanatory power by suggesting detailed changes (see above). The undesired, and perhaps paradoxical, side effect is that their accumulated suggested changes only further reduce the analytical power of the theory. We identified two forms of suggested changes: concept stretching and concept proliferation (cf., Collier \& Mahon, 1993). Concept stretching happens when a concept is fitted to a concrete case, but in such a way that the meaning of the concept is broadened well beyond its initial meaning. Because of the ambiguity of the various modes of incremental change and other concepts introduced (their boundaries are not clear, their definitions are not stable), concept stretching is likely to happen, as we have indicated before. It is often not clear where one mode begins and the other ends. This partly explains the often observed sequencing, and sometimes results in situations where a mode can be 'stretched' so far that a single observation of change can be captured as layering, conversion, and drift (extensively discussed above).

Related to concept stretching, conceptual proliferation may happen when scholars observe institutional change that cannot be directly or clearly captured by any of the modes available. We observed the explicit proliferation of novel modes of change in 6 of the 45 articles studied (13\%). Some examples from our meta-review are illustrative here: the introduction of institutional shrinkage, institutional copying, and institutional wedging. Institutional shrinkage captures a process of 'active and deliberate scaling back of the main dimensions which characterized an institution', which ultimately results in a situation where institutions 'become eroded' (Steinlin \& Trampusch, 2012, pp. 254-255). Institutional copying captures a process of institutional change where two new institutions are introduced in the European monetary context that copy elements of earlier institutions (Verdun 2015). Institutional wedging captures a process in which new elements are added to an institution 'that can 
(depending on future events and struggles) change the logic of institutional functioning' but that in this specific case did not result in the sought after change (Todd, 2011, p. 840, emphasis and brackets in the original).

We are critical to such concept stretching and proliferation. Concept stretching may become problematic when a meta-analysis compares cases that are wrongly captured as similar modes - a case of conversion wrongly captured as layering pollutes the dataset in a metaanalysis of layering. Relatedly, the dataset underlying a meta-analysis of layering may be polluted if it is not fully clear when cases identified as layering relate to a process of change, an outcome of change, or a strategy to achieve change. Likewise, concept proliferation may undermine the comparative advantage of the theory if 'novel' concepts are introduced that are

mere marginal variations of the existing ones. To turn back to the three examples: Institutional shrinkage very much resembles institutional exhaustion. Institutional copying very much resembles institutional layering based on institutional isomorphism (DiMaggio \& Powell, 1991). Institutional wedging very much resembles institutional layering, but without the anticipated changed outcome. An ultimate consequence of the ambiguity of the 'original' modes and proliferation of 'novel' ones is that empirical findings of gradual institutional change are spread thinner and thinner over an ever growing number of concepts.

\section{Discussion}

The selection process of our meta-analysis and the flow diagram (Figure 2) have already provided a major insight: while the theory of Thelen and her collaborators is frequently cited, it has seen limited application. Even in the set of 102 articles that were likely empirical and cite either of the two key books, about half of them appear to make obligatory rather than 
necessary citations. We have shown, further, that actual application of the modes in empirical work is rare, and the application of change agents is even rarer.

Scholars seem to feel more comfortable using the various concepts (modes and agents) to describe instances of gradual institutional change, rather than to use them to evaluate these instances - let alone to put the theory and expectations introduced to the test. What is more, the few scholars that have put them to the test often found no support for the expectations. In addition, more often than not scholars experience complications with applying the theory and heuristic to the letter. This has resulted in on-going modifications to the concepts in the empirical literature.

What may explain this situation? We argue that it is, first, a product of the fluidity of the different concepts introduced. It is, for example, not clear where a mode begins and where it ends. Second, it is product of the lack of clarity concerning what a mode of change actually is - a process, an outcome, or a strategy. The same holds true, third, for the conceptualisation of change agents. Fourth, it is a product of the assumed causal links in the heuristic framework introduced in Explaining Institutional Change (see Figure 1). These make the theory somewhat rigid, which harms its explanatory (and even descriptive) power. This becomes, for example, clear in instances of sequencing of modes of change (see above). Because concrete cases of incremental change will likely be much messier and less clear-cut than what the heuristic suggests, scholars are unlikely to see the theory and expectations confirmed (see related discussions in Maggetti, 2014; Rocco \& Thurston, 2014).

How problematic is this situation? It depends. If the baseline assumption is that without these concepts it is very difficult to study gradual institutional change at all, then it is easy to brush aside the critiques. Whilst the theory is flawed, it could then be argued, scholarship is still better off with it than without it. But this would be a faulty argument because others have introduced alternative conceptualisations for gradual institutional change, some of which form 
the basis of Thelen and her collaborators' theory - these include mimicry and institutional isomorphism (DiMaggio \& Powell, 1991), institutional bricolage and translation (Campbell, 2010), and institutional erosion (Oliver, 1992, Hassel, 2002). Whilst these may come with their own flaws, there does not seem to be a lack of concepts to explain gradual institutional change, not only with regard to historical institutionalism and the related literature but also with regard to policy analysis in a broader sense (see also Berk, Galvan, \& Hattam, 2013; van der Heijden, 2011).

We, therefore, argue that this is a problematic situation. The advantage of a theory and its concepts should be, apart from a reduction of complexity, that it allows for comparison across cases (see similar arguments in Collier \& Mahon, 1993; Mahoney \& Thelen, 2015). Of course, Thelen and her collaborators may have deliberately kept their definitions somewhat fluid to allow others to use their terminology for studying processes underlying change, the outcomes of such processes, and whether or not such processes can be used strategically, deliberately, and effectively (cf., Mahoney \& Thelen, 2010). Yet, after over a decade of theory and loose application, we now face a body of very heterogeneous work that is very difficult to compare —while it all builds (or claims to build) on the same sources. We feel this is predominantly a result of the introduced typology of modes of change which are not mutually exclusive, and thus has limited analytical value in distinguishing and comparing similar and different processes of change across place and time. In addition, over time the expected relationships between modes of change and their contexts (including the concept of change agents) have changed, which further limits the comparative advantage of a theory and heuristic (see particularly the differences between Hacker, 2004, Mahoney \& Thelen, 2010, and Hacker, Pierson, \& Thelen, 2015).

We consider another complication of the theory to be that it is not truly capable of anticipating the mode of change that will occur under specific conditions. The modes of 
change, change agents, and other concepts introduced are extremely valuable in ex-post descriptions of gradual institutional change. They have little value in ex-ante research, however-a criticism that is more foundational to gradual change scholarship. While Thelen and her collaborators have always been very careful not to claim too much with respect to the predictive power of their theory, they do give the illusion of a predictive theory, particularly in the unique linking of institutional contexts with change agents and modes of change (see Figure 1). However, scholars have not been able to find (wide) support for the expressed relationships, and many have found the theory too limited for their empirical research and in response have expanded it.

That all being said as a critique to the theory, the broader scholarly community needs to be critiqued too. After all, there is a tendency to cite the theory but not apply it. The pattern of 'obligatory' citations results in a situation of a well-cited theory giving it the false illusion of having strong evaluative and analytical power.

\section{Conclusion: Avenues for future research}

Applying the PRISMA method for meta-analyses, we have reviewed a body of literature that builds on two seminal works in the development of the theorising on incremental institutional change: Beyond Continuity (Streeck \& Thelen, 2005) and Explaining Institutional Change (Mahoney \& Thelen, 2010). These books and related works have provided an appealing and widely cited theory on incremental institutional change. The meta-review presented has, however, provided considerable quantitative support for three main critiques that have been plaguing the theory since its early days, and has expressed an additional critique.

In our opinion, building on the meta-analysis presented, the research programme started by Thelen around 2000, and followed by her collaborators and others for over 15 years now, has 
seen limited progression as a means to better understand gradual institutional change. But before we move to our critique of this limited progression, we wish to stress that their work deserves credit for having provided a single and workable language to better describe past cases of gradual change. The modes of change have inspired and supported the development of a substantial pool of empirical data on gradual institutional change.

Describing, however, is not the same as evaluating. Evaluation ultimately asks for comparison to understand whether, for example, one mode of change is more desirable than another or no change at all; whether one observed instance of layering results in better outcomes than another and why, and so on. The vagueness in the theory has, unfortunately, resulted in a pool of empirical data that is very difficult to systematically compare - the theory lacks evaluative power. Lacking evaluative power, the theory logically lacks 'predictive' power to anticipate future cases of gradual change. If we cannot understand why and how incremental change happens more generally (that is, based on evaluative comparative analysis) in 'the now', how then can we extrapolate to the future? While it may be questioned whether the social sciences are capable of developing predictive theories in the first place (Goertz \& Mahoney, 2012; Popper, 2002 [1935]), the theory presented by Thelen and her collaborators creates the illusion of being predictive - modes of change are uniquely assigned to specific contexts, hypotheses are introduced, and so on.

We are hopeful, nevertheless, about the future application and development of the theory. A group of scholars have been extremely diligent in applying it to the letter, seeking to understand its possibilities and limitations (e.g., Angelin et al., 2014; Emmenegger, 2015; Lambert, 2016). Keeping in mind the difficulties with the theory, we still feel that a careful and transparent application of the theory (that is open about the potential limits in the empirical application) is one of the ways forward in order to come to a coherent body of work - not only to allow for comparisons of various modes within this theory, but also to 
compare observations of gradual institutional change with less gradual ones. Here, it also remains to be seen how prominent change agents and the various expectations introduced will be in future studies - or whether the different modes of institutional change will remain more popular. Yet, understanding that diligent application is less exciting than exploring new avenues, we have four suggestions for roaming paths less travelled.

A first less travelled path is the sequencing of modes: the theory appears too crude to deal with fine-grained insights of sequences, and future work might explore whether specific sequences of modes are more likely than others. Current work on sequencing often highlights that sequences start with or result in layering, but we lack evidence whether this is a general pattern or not (cf., Barnes, 2008).

A second is combining different theories from different schools of comparative historical analysis (or even policy analysis more generally) to come to a more holistic understanding of a concrete case of change. An exciting research avenue would be to study a concrete case through the lenses provided by different theories (cf., van der Heijden, 2013, Trampusch, 2014; Hall \& Taylor, 1996). This can be considered an alternative to comparing observations within the theory and may help addressing the lack of evaluative power of the theory itself.

Third, the limited attention to institutional exhaustion in the empirical literature may be a direct result of the exclusion of the concept from the broader theory. We feel the current set of modes is too limited to gain a better understanding of what causes the diminishing and termination of institutions. We, therefore, argue for further exploration of concepts such as institutional exhaustion, institutional erosion, and institutional shrinkage to contrast the work on expanding institutions with insights on declining ones (cf., Busemeyer \& Trampusch, 2013). 
Fourth and final is the limited attention paid to (unexpected) institutional stability and failed attempts at gradual change-limited when compared with attention given to successful (gradual) change. Whilst some attempts to gradually change institutions are successful, not all are). More systematic exploration of stability in situations of organised attempts to change institutions may shed new light on the modes of change as well.

A final warning is in place here, however. These four alternative research avenues will in themselves not help in overcoming what we consider the main limitation of the theory and its (current) application: a lack of clarity and precision, and a tendency to describe gradual institutional change rather than evaluate it.

\section{Acknowledgements}

The authors wish to thank the editor of the journal and three anonymous reviewers for helpful suggestions to improve an earlier version of this article. All errors are the authors'.

\section{References}

Ackrill, R. \& Kay, A. (2006). "Historical-Institutionalist Perspectives on the Development of the EU Budget System." Journal of European Public Policy 13(1), 113-133.

Angelin, A., Johansson, H., Koch, M. (2014). "Patterns of Institutional Change in Minimum Income Protection in Sweden and Germany." Journal of International and Comparative Social Policy 30(2), 165-179.

Barnes, J. (2008). "Courts and the Puzzle of Institutional Stability and Change: Administrative Drift and Judicial Innovation in the Case of Asbestos.” Political Research Quarterly 61(4), 636 -648 .

Baumgartner, F. R. \& B. D. Jones (1993). Agendas and Instability in American Politics. Chicago: University of Chicago Press. 
Baumgartner, F. R. \& B. D. Jones (2009). Agendas and Instability in American Politics - second edition. Chicago: University of Chicago Press.

Béland, D. (2007). "Ideas and Institutional Change in Social Security: Conversion, Layering, and Policy Drift.” Social Science Quarterly 88(1), 20 - 38.

Béland, D. (2010). "Policy Change and Health Care Research." Journal of Health Politics, Policy and Law 35(4), 615-641.

Beramendi, P. \& Rueda, D. (2014). "Inequality and Institutions: The Case of Economic Coordination.” Annual Review of Political Science 17, 251-271.

Berk, G., Galvan, D., \& Hattam, V. (Eds.). (2013). Political Creativity. Philadelphia: University of Pennsylvania Press.

Boas, T. C. (2007). "Conceptualizing Continuity and Change. The Composite-Standard Model of Path Dependence.” Journal of Theoretical Politics 19(1), 33-54.

Busemeyer, M. \& Trampusch, C. (2013). "Liberalization by Exhaustion. Transformative Change in the German Welfare State and Vocational Training System." Zeitschrift für Sozialreform 59(3), 291-312.

Campbell, J. L. (2010). "Institutional Reproduction and Change”, in: The Oxford Handbook of Comparative Institutional Analysis, eds. G. Morgan, J. L. Campbell, C. Crouch, O. Pedersen, R. Whitley, Oxford: Oxford University Press, 87-115.

Capano, G. \& M. Howlett (2009). "Introduction: The Determinants of Policy Change." Journal of Comparative Policy Analysis 11(1), 1-5.

Carey, G., \& Crammond, B. (2015). “What Works in Joined-Up Government?” International Journal of Public Administration (Online first). doi:10.1080/01900692.2014.982292

Collier, D. \& J. Mahon (1993). “Conceptual 'Stretching' Revisited." American Political Science Review 87(4), 845-855.

DiMaggio, P. J. \& Powell, W. P. (1983). “The Iron Cage Revisited: Institutional Isomorphism and Collective Rationality in Organizational Fields.” American Sociological Review 48(2), $147-160$. 
Duit, A. (2007). “Path Dependency and Institutional Change.”, Public Administration 95(4), 1097-1118.

Ellingsæter, A.-L. (2014). "Nordic Earner-Carer Models - Why Stability and Instability?" Journal of Social Policy 43(3), 555-574.

Emmenegger, P. (2015). “The Politics of Job Security Regulations in Western Europe.” Politics \& Society 43(1), 89-118.

Fenger, M., van der Steen, M., \& van der Torre, L. (2014). “The Responsiveness of Social Policies. Explaining Institutional Change in three Policy Domains.” International Review of Administrative Sciences 80(3), 659-680.

Funk, R.J. \& Hirschman, D. (2014). "Derivatives and Deregulation. Financial Innovation and the Demise of Glass-Steagall.” Administrative Science Quarterly 59(4), 669-704.

Genschel, P. (1997). “The Dynamics of Inertia: Institutional Persistence and Institutional Change in Telecommunications and Health Care.” Governance 10(1), 43-66.

Goertz, G., \& Mahony, J. (2012). A Tale of Two Cultures. Princeton: Princeton University Press.

Gozman, D. \& Currie, W. (2014). "The Role of Rules-Based Compliance Systems in the new EU Regulatory Landscape: a Post-Financial Crisis Study of Displacement Mechanisms." Journal of Enterprise Information Management 27(6), 817 - 830.

Hacker, J.S., Pierson, P., Thelen, K. (2015). "Drift and Conversion: Hidden Faces of Institutional Change", in: Advances in Comparative-Historical Analysis, eds. J. Mahoney \& K. Thelen, Cambridge: Cambridge University Press, 180-208.

Hacker, J. S. (2004). "Privatizing Risk without Privatizing the Welfare State.", American Political Science Review 98(2), 243 - 260.

Hall, P. (2015). "Social Policy-Making for the Long Term." PS 48(2), 298-291.

Hassel, A. (2002). “The Erosion Continues: Reply.” British Journal of Industrial Relations 40(2), 309-317. 
Hudson, J./ Hwang, G./ Kühner, S. (2008). "Between Ideas, Institutions and Interests: Analysing Third Way Welfare Reform Programmes in Germany and the United Kingdom.” Journal of Social Policy 37(2), $207-230$.

Immergut, E. M. \& Anderson, K. M. 2008, "Historical Institutionalism and West European Politics”, West European Politics 31(1-2), 345 - 369.

Koning, E.A. (2016). "The three Institutionalisms and Institutional Dynamics: Understanding Endogenous and Exogenous Change." Journal of Public Policy, DOI: 10.1017/S0143814X15000240.

Lambert, N. (2016). "Internal Diversity and Change in the UK: The Changing Forms and Levels of Coordination in Wages and Working Conditions within the Ceramic Tableware Sector 19452008." Economic and Industrial Democracy 37(1), 145-170.

Lomazoff, E. (2012). “Turning (Into) 'The Great Regulating Wheel': the Conversion of the Bank of the United States, 1791-1811.” Studies in American Political Development 26(1), 123.

Maggetti, M. (2014), "Institutional Change and the Evolution of the Regulatory State:

Evidence from the Swiss Case.” International Review of Administrative Sciences 80(2), 276 297.

Mahoney, J. \& Thelen, K. (2010). “A Theory of Gradual Institutional Change”, in Explaining Institutional Change., eds. J. Mahoney, K. Thelen, Cambridge/New York: Cambridge University Press, , $1-37$.

Mahoney, J. \& Thelen, K. (eds.) 2015, Advances in Comparative-Historical Analysis. Cambridge: Cambridge University Press.

Mettler, S., (2016). "The Policyscape and the Challenges of Contemporary Politics to Policy Maintenance." Perspectives on Politics 14(2), 369-390.

Mizrahi, S. \& Tevet, E. (2014). “A New Institutionalism Analysis of Electricity Sector Reform: Theoretical and Comparative Perspectives.” Public Administration Quarterly 38(1), 3-37.

Nichols, C. (2015). "Reagan Reorders the Political Regime: A Historical-Institutional Approach to Analysis of Change." Presidential Studies Quarterly 45(4), 703-726. 
Nicolaisen, H. (2014). "The End of the Normal Working Day? ? A Study of Change in Irish, Norwegian and Swedish Banking.” Economic and Industrial Democracy 35(2), 245-266.

Oliver, C. (1992). "The Antecedents of Deinstitutionalization.” Organization Studies 13(4), 563-588.

Parker, R., \& Parenta, O. (2008). "Explaining Contradictions in Film and Television Industry Policy: Ideas and Incremental Policy Change through Layering and Drift." Media Culture Society 30(5), 609-622.

Pierson, P. (2004). Politics in Time. Princeton, Princeton University Press.

Popper, K. (2002 [1935]). The Logic of Scientific Discovery. London, Routledge.

Rhodes, R. A. W., Binder, S. A., \& Rockman, B. A. (2006). The Oxford Handbook of Political Institutions. Oxford: Oxford University Press.

Rixen, T. \& Viola, L. A. (2015). "Putting Path Dependence in its Place: Toward a Taxonomy of Institutional Change.” Journal of Theoretical Politics 27(2), $301-323$.

Rocco, P. \& Thurston, C. (2014). "From Metaphors to Measures: Observable Indicators of Gradual Institutional Change.” Journal of Public Policy 34(1), 35 - 62.

Schickler, E. (2001). Disjointed Pluralism. Princeton: Princeton University Press.

Seeleib-Kaiser, M. \& Fleckenstein, T. (2007). "Discourse, Learning and Welfare State Change”, Social Policy \& Administration 41(5), 427 - 448.

Sheingate, A. (2010). "Rethinking Rules." in Explaining Institutional Change., eds. J. Mahoney, K. Thelen, Cambridge/New York: Cambridge University Press, 168 - 203.

Shpaizman, I. (2014). "Ideas and Institutional Conversion through Layering: The Case of Israeli Immigration Policy.” Public Administration 92(2), 1038 - 1053.

Steinlin, S. \& Trampusch, C. (2012), "Institutional Shrinkage: The Deviant Case of Swiss Banking Secrecy." Regulation and Governance 6(2), 242-259.

Streeck, W. (1997). "Beneficial Constraints. On the Economic Limits of Rational Voluntarism." In J. R. Hollingsworth \& R. Boyer (Eds.), Contemporary Capitalism. New York: Cambridge University Press, 197-219. 
Streeck, W. \& Thelen, K. (2005). "Introduction: Institutional Change in Advanced Political Economies.” In W. Streeck, K. Thelen (Eds.), Beyond Continuity. Institutional Change in Advanced Political Economies, Oxford: Oxford University Press, 1 - 39.

Thatcher, M., \& Coen, D. (2008). "Reshaping European Regulatory Space: An Evolutionary Analysis.” West European Politics 31(4), 806-836.

Thelen, K. (1999). "Historical Institutionalism in Comparative Politics", Annual Review of Political Science 2, $369-404$.

Thelen, K. (2000). "Timing and Temporality in the Analysis of Institutional Evolution and Change." Studies in American Political Development 14(Spring), 101-108.

Thelen, K. (2009). “Institutional Change in Advanced Political Economies.” British Journal of Industrial Relations 47(3), 471-498.

Todd, J. (2011). "Institutional Change and Conflict Regulation: the Anglo-Irish Agreement (1985) and the Mechanisms of Change in Northern Ireland.” West European Politics 34(4), $838-858$.

Trampusch, C. (2014). "Why Preferences and Institutions Change: A Systematic Process Analysis of Credit Rating in Germany.” European Journal of Political Research 53(2), 328 344.

Valman, M. (2013). "Institutional Stability and Change in the Baltic Sea." Marine Policy 38(1), 54-64.

Van der Heijden, J. (2010). “A Short History of Studying Incremental Institutional Change: Does Explaining Institutional Change Provide any new Explanations?" Regulation \& Governance, 4(2), 230-243.

Van der Heijden, J. (2011). "Institutional Layering: A Review of the Use of the Concept." Politics, 31(1), 9-18.

Van der Heijden, J. (2013). "Different but Equally Plausible Narratives of Policy Transformation: a Plea for Theoretical Pluralism." International Political Science Review, 34(1), 57-73. 
Van der Heijden, J. (2016). "Looking Differently at Legal Change: Layering, Conversion, Drift, Displacement and Exhaustion in the Development of Dutch Construction Regulation.” KLRI Journal of Law and Legislation, 6(1), 82-111

Verdun, A. (2015). “A Historical Institutionalist Explanation of the EU's Responses to the Euro Area Financial Crisis”, Journal of European Public Policy 22(2), 219 - 237.

Weishaupt, J. T., Ebbinghaus, B, \& Wendt, C. (2013). "Editorial. Der Umbau des Wohlfahrtsstaates in Krisenzeiten.”, Zeitschrift für Sozialreform 59(3). 279-290. 
Figure 1: Contextual and Institutional Sources of Change Agents

Characteristics of the targeted institution

\begin{tabular}{lr|c|c|}
\cline { 3 - 4 } & & $\begin{array}{c}\text { Low level of discretion in } \\
\text { interpretation/enforcement }\end{array}$ & $\begin{array}{c}\text { High level of discretion in } \\
\text { interpretation/enforcement }\end{array}$ \\
\cline { 3 - 4 } & Strong veto & Subversives & Parasitic symbionts \\
Characteristics & possibilities & (layering) & (drift) \\
\cline { 3 - 4 } $\begin{array}{l}\text { of the political } \\
\text { context }\end{array}$ & Weak veto & Insurrectionaries & Opportunists \\
(conversion)
\end{tabular}

Source: Mahoney/Thelen 2010: 28 
Figure 2: PRISMA flow diagram
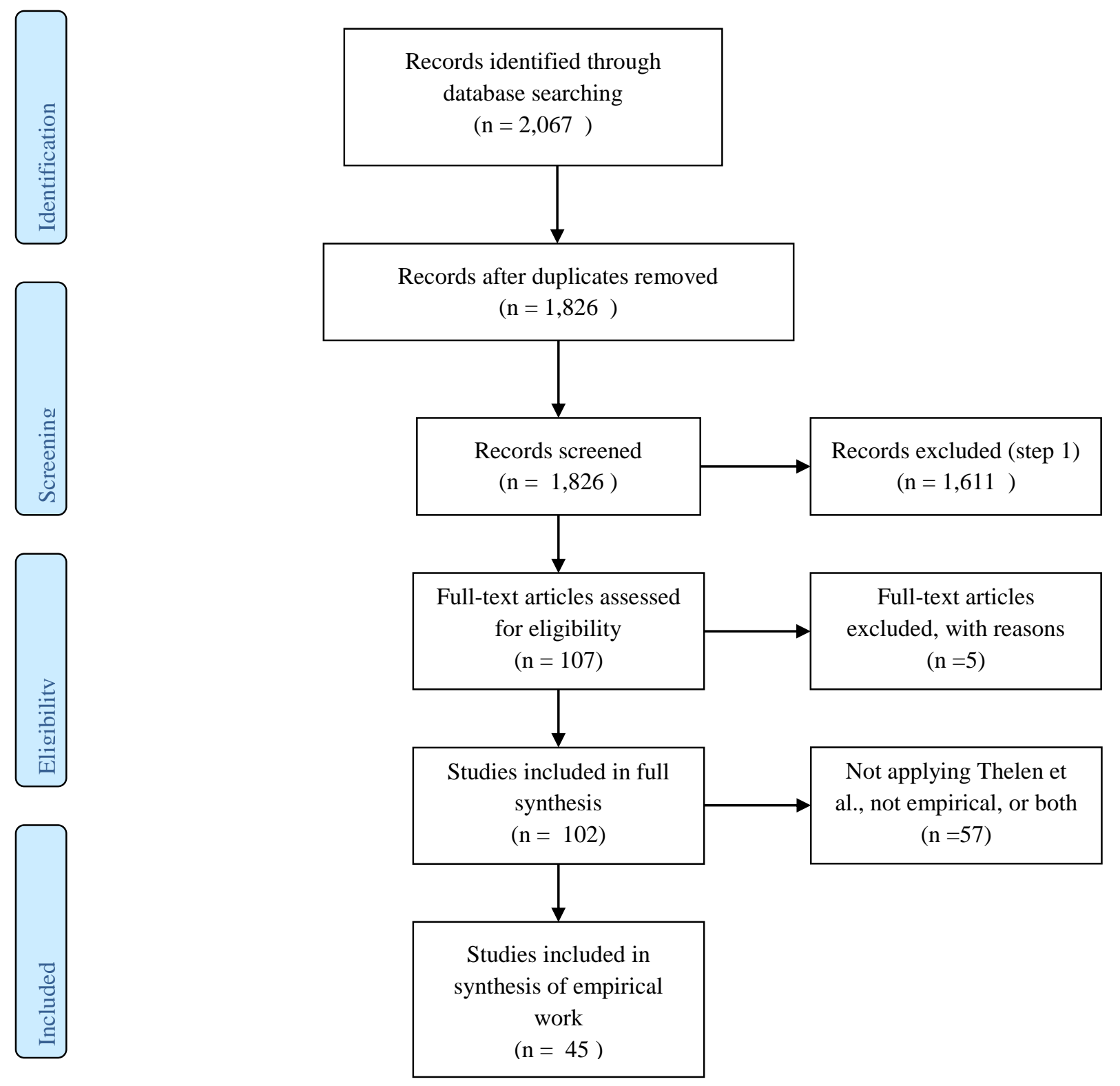